\title{
Pekerja Filem dan Isu Bayaran dalam INDUSTRI Filem MALAYSIA
}

\author{
Ahmad Fadhli Ab Wahab @ Masri \\ Universiti Sains Malaysia, Malaysia \\ fadhliwahabmalaysia@gmail.com \\ Rohani Hashim \\ Universiti Sains Malaysia, Malaysia \\ rohani@usm.my
}

\begin{abstract}
FILM WORKERS AND PAYMENT ISSUES IN MALAYSIAN FILM INDUSTRY

Film workers in Malaysia were having problems of not getting paid, partially paid or payments delayed by the employers. This research is to investigate the causes of payment issues in Malaysian film industry; to examine the effects of the problems to the film workers; and to provide solutions to the problems. A study was undertaken by interviewing a number of film workers in Malaysian film industry. The findings show that the major causes of payment issues are low clarity in contract employment, poor payment procedure, low understanding of film workers regarding employment contract, ineffectiveness of the film workers associations and insufficient cash flow by employers.
\end{abstract}

Keywords: payment issue, film workers, Malaysian film industry

\section{PENGENALAN}

Sebagai salah satu industri kreatif yang penting, industri filem merupakan sumber penting dalam pertumbuhan ekonomi dan percambahan budaya bagi sesebuah negara maju. Dalam perspektif ekonomi dan sosiobudaya Malaysia sebagai contoh, industri kreatif memberi sumbangan sebanyak RM9.4 bilion kepada Keluaran Dalam Negara Kasar (KDNK) negara pada tahun 2008 dan berpotensi menjana ekonomi berpendapatan tinggi serta memartabatkan budaya bangsa (Dasar Industri Kreatif Negara, 2009). Justeru, Malaysia mampu menjadikan industri kreatif sebagai sumber pekerjaan dan pendapatan negara, seterusnya mencapai sasaran ekonomi negara berpendapatan tinggi. Pembayaran hasil seni kreatif telah dikenal pasti sebagai salah satu bidang keutamaan di dalam industri perfileman Malaysia. Amalan pembayaran yang cekap dan tepat pada masanya dalam pembikinan filem merupakan faktor utama yang dapat menyumbang kepada kejayaan sesebuah projek. 
Tinjauan mengenai prestasi pembayaran telah menunjukkan bahawa industri perfileman khususnya terdedah pada budaya pembayaran lewat, tidak setimpal, malahan tiada bayaran. Isu bayaran hasil kerja pekerja filem merupakan inti pati perbualan warga industri kreatif di Malaysia. Isu ini telah lama dan wujud sejak 1950-an, iaitu pada zaman P. Ramlee lagi. Isu bayaran kepada pekerja filem menjadi semakin buruk apabila sepuluh tahun kemudian berlaku krisis antara pelakon dan majikan walaupun para pelakon mempunyai pengalaman antara lima hingga tujuh tahun dalam industri perfileman Malaysia (Ab Samad \& Daeng Haliza, 2011). P. Ramlee sebagai Presiden Persatuan Artis Filem Malaya (PERSAMA) pernah menuntut bayaran untuk pelakon yang tidak pernah dinaikkan gaji mereka walaupun mereka telah bekerja lebih lima tahun (Jamil Sulong 2007:154). Sepanjang sepuluh tahun penubuhannya, PERSAMA telah mengadakan mogok sebanyak dua kali bagi menuntut kenaikan gaji. Kesan daripada mogok tersebut telah mendorong kenaikan gaji pelakon (Daeng Haliza \& Ab Samad, 2011).

Dalam konteks semasa, masalah pembayaran gaji pekerja filem masih berlaku. Keadaan ini diakui oleh pengarah Hairie Othman yang membuat laporan polis kerana tidak berpuas hati terhadap syarikat produksi filem yang tidak melunaskan bayaran produksi (Kemalia, 2010). Masalah yang sama turut melanda pengarah dan pelakon tempatan. Antaranya Shuhaimi Zulkefli yang menyatakan bahawa syarikat produksi yang menerbitkan Perangsang Rentap masih belum menerima bayaran walaupun filem itu telah ditayangkan (Amirul, 2018). Selain itu, pelakon Pierre Andre dan Nabila Huda menyatakan kekesalan terhadap pihak produksi yang gagal memberikan bayaran setimpal dan melakukan pembayaran pada masa yang ditetapkan (Serimah, 2020; Nur Asyikin, 2021). Justeru, artikel ini cuba mengenal pasti faktor-faktor yang membawa kepada masalah pembayaran gaji pekerja filem dan kesannya kepada mereka.

\section{Pekerjaan dalam Industri Filem}

Terdapat dua jenis tenaga kerja dalam sesebuah produksi perfileman, iaitu pekerja tetap dan pekerja bebas (freelancer) (Weiss \& Faulkner, 1983; Dex, et.al, 2000). Pekerja tetap adalah mereka yang berada di pejabat dan melakukan kerja-kerja pengurusan dan pentadbiran seperti kerani, setiausaha dan penerbit dan dibayar gaji bulanan. Pekerja bebas adalah mereka yang diambil dari luar syarikat dan bekerja untuk sesuatu projek dalam tempoh tertentu dan dibayar mengikut kontrak. Antaranya termasuklah pengarah filem, pengarah seni, jurukamera, penata cahaya, pelakon, jurusolek, pengurus produksi, penjaga prop, penjaga kesinambungan, pereka set, pereka kostum, juruelektrik dan jurugegas. Kebanyakan pekerja filem di Malaysia adalah bekerja sebagai pekerja bebas. Pemilihan kerjaya pekerja bebas membantu memantapkan produktiviti sesebuah produksi filem melalui kemahiran kraf, estetika dan keusahawanan mereka (Bound et al., 2013). Antara kelebihan pekerja bebas termasuklah jurang antara satu kontrak pekerjaan dengan kontrak yang lain dapat memberikan masa tambahan untuk melakukan pekerjaan peribadi dan bersama keluarga; bebas memilih dan menguruskan projek yang diminati; berpeluang untuk terlibat dalam pelbagai produksi dan kru; boleh mengembangkan rangkaian rakan sekerja; dan berkemampuan untuk menambah pendapatan (Bound, et al.; 2013; USG Film Alliance Task Force, 2014). Kelemahan terbesar bagi pekerja bebas adalah ketidakstabilan kerjaya yang boleh menyebabkan masalah kewangan, tidak menerima ganjaran bekerja seperti insurans kesihatan, keselamatan kurang terjamin dan kesukaran mendapatkan kontrak seterusnya 
(USG Film Alliance Task Force, 2014; Rowlands, 2009). Di Singapura, pekerja bebas terdedah dengan kerja yang kurang terjamin, selalu dibebani dengan kerja berat dan lebih masa serta berpotensi menerima bayaran lewat. Malahan ada yang tidak menerima bayaran langsung (Bound, et al., 2013).

Dalam dunia perfileman Malaysia, pekerja-pekerja filem bekerja dalam waktu yang tidak menentu. Contohnya, ketika menerbitkan sebuah filem seram, penggambaran filem banyak dilakukan pada waktu malam. Oleh itu, pekerja amat diperlukan untuk bekerja lebih masa sehingga lewat malam. Syafil (2019) menjelaskan bahawa sesetengah pelakon tanpa mengira gender mengakui mereka terpaksa bekerja dalam produksi yang berjadual padat dan masa yang tidak menentu. Tindakan ini dilakukan untuk mengurangkan kos sewaan berkenaan agar tidak melebihi peruntukan yang telah ditetapkan. Pembayaran pekerja filem diberi berdasarkan jenis pekerjaan mereka. Sebagai contoh, pelakon dibayar mengikut populariti dan pengalaman berlakon. Namun, pelakon baharu dan muda dari segi usia dibayar dalam kadar yang berbeza berbanding dengan pelakon veteran yang berpengalaman. Keadaan ini memberi kesan kepada pelakon yang lebih lama menceburi bidang ini (Kool FM, 2019).

Bayaran yang diberikan kepada pekerja filem adalah mengikut tempoh atau jangka masa sesebuah produksi dilakukan. Kebiasaannya, pembayaran dipecahkan kepada tiga peringkat (Qarami, 2020). Sebahagiannya dibayar sebelum sesebuah projek bermula manakala sebahagiannya diberikan ketika pertengahan projek berlangsung. Baki bayaran akan diselesaikan sebaik sahaja projek produksi berjaya ditamatkan. Namun, pembayaran ini seringkali dianggap tidak sistematik dan berbeza mengikut syarikat produksi filem. Terdapat juga syarikat produksi yang membayar gaji pekerja secara berperingkat (Qarami, 2020). Pembayaran gaji melalui perkongsian keuntungan juga kadangkala dilakukan bagi sesetengah syarikat produksi terutamanya kepada pelakon dan pengarah filem. Kualiti filem dan lakonan dapat ditingkatkan melalui perkongsian keuntungan bagi sesebuah filem yang mencapai tahap 'pecah panggung' (Box-Office). Ini kebiasaannya dilakukan oleh sesetengah syarikat produksi seperti Metrowealth International Group (MIG) yang melakukan tradisi pemberian bonus kepada pelakon dan kakitangan yang menjayakan filem-filem terbitannya (MStar, 27 Januari 2011).

Sesebuah syarikat filem memperoleh bajet atau peruntukan bagi sesebuah produksi melalui pembiayaan kendiri (Ridzuan, 2021), pinjaman bank (Siti Azira, (2009), Skim Pinjaman Filem Cereka (SPFC) dan perolehan Dana Kandungan Digital dari Perbadanan Filem Malaysia (FINAS) (FINAS 2020) dan Pakej Rangsangan Industri Kreatif (PRISMA) dari Kementerian Komunikasi dan Multimedia Malaysia (Kementerian Komunikasi dan Multimedia, 2021). Terdapat juga projek filem yang mempunyai pelabur dan penaja daripada syarikat usahawan yang besar seperti ahli perniagaan kosmetik, Datuk Aliff Syukri Kamarzaman, yang menaja filem Badang arahan A. Razak Mohaideen (Muhamad Fairoz, 2017). Namun, kualiti sesebuah filem dipengaruhi oleh pelabur. Malahan, pelabur turut bertindak menyelia kualiti dan bayaran pekerja filem. Dengan ini, dapat dikatakan bahawa pembayaran gaji pekerja filem turut dipengaruhi oleh pelabur kerana mereka mengawal perbelanjaan sesebuah produksi. Oleh demikian, kemungkinan untuk sesebuah bajet dipotong atau dikaji semula adalah amat tinggi hingga mempengaruhi pembayaran hasil kerja pekerja filem.

Persatuan dan aktiviti seni amat penting dalam pembangunan industri kreatif. Di Malaysia, terdapat beberapa persatuan filem dan mempunyai fungsi yang tersendiri. Misalnya, Persatuan Seniman Malaysia (SENIMAN) membantu dalam hal ehwal pelakon- 
pelakon seni filem dalam hal-hal seperti kesinambungan pekerjaan dan sebagainya (Daeng Haliza, 2011) manakala Persatuan Pekerja Profesional Filem Malaysia (PROFIMA) membantu para pekerja filem untuk terus kekal hidup dalam industri (Daeng Haliza, 2011). Persatuan Penerbit Filem Malaysia (PFM) pula melestarikan projek perfileman agar penerbit-penerbit mampu bertahan dalam industri manakala Film Directors' Association of Malaysia (FDAM) memperjuangkan hak pengarah filem dalam industri seperti hal-hal berkaitan kesinambungan pengarah itu sendiri (Daeng Haliza, 2011). Dalam pada itu, Persatuan Karyawan Malaysia (KARYAWAN), Malaysia Karyawan Hiburan Tanah Air (MAHKOTA) dan Creative Content Association of Malaysia (CCAM) juga membantu untuk memastikan kelestarian industri perfileman di Malaysia. Mulai 1 Januari 2020, pekerja filem diberi caruman Kumpulan Wang Simpanan Pekerja (KWSP) dan Pertubuhan Keselamatan Sosial (PERKESO) sebagaimana yang diperkenalkan oleh Perbadanan Kemajuan Filem Nasional Malaysia (FINAS) melalui penggubalan Akta FINAS 1981 (Akta 244). Akta ini mewajibkan penerbit selaku majikan membuat caruman untuk pekerja masing-masing. FINAS boleh menarik balik Sijil Perakuan Penggambaran Filem sekiranya penerbit berdegil daripada mencarum bahagian mereka (Hanisah, 2019).

\section{Isu Pembayaran dalam Kalangan Pekerja Filem di Malaysia}

Isu biasa yang melanda industri perfileman negara hari ini tertumpu pada kos pembikinan sesebuah filem yang menelan belanja besar. Filem J Revolusi misalnya, menelan kos pembikinan sebanyak RM3 juta dan mendapat kutipan tiket sebanyak RM7 juta selepas tayangan manakala filem Abang Long Fadil 2 menelan kos RM3.2 juta dan mendapat kutipan tiket sebanyak RM17 juta selepas tayangan (Rozdan \& Mohd Aizat, 2017). Ini menunjukkan bahawa kos sesebuah produksi memerlukan bajet yang tinggi dan sangat menguntungkan. Justeru, adalah wajar industri ini mampu menampung kos hasil kerja pekerja filem di Malaysia bagi sesebuah produksi. Namun, masih terdapat syarikat filem yang gagal membayar gaji pada masa yang ditetapkan, membayar upah tidak setimpal dan tiada pemberian bonus pekerja walaupun sudah mendapat keuntungan besar. Pengarah seperti Shuhaimi Zulkefli, misalnya masih belum mendapat bayaran pembikinan filem Perangsang Rentap yang ditayangkan pada 2017 daripada syarikat produksi Unique Twins. Hal ini berlaku kerana pekerja filem masih tidak mempunyai pemahaman semasa menerima tawaran bekerja di sesebuah syarikat penerbitan filem dengan mengabaikan kontrak yang sepatutnya ditandatangani antara majikan dengan pekerja sebelum produksi bermula (Amirul, 2018).

Pada masa yang sama, Rudy (2019) menyatakan bahawa filem Sangkar yang bernilai RM3 juta (tidak termasuk kos promosi) yang melibatkan empat produksi tempatan, iaitu Infinitus Gold, Primeworks Studio, Astro Shaw, dan MM2 Entertainment telah memberi kesan tertentu dalam proses produksi. Misalnya, kos promosi menyebabkan bajet kos pembikinan filem itu diturunkan bagi menampung keperluan promosi sesebuah filem. Kos bayaran pekerja filem dalam sesebuah produksi berkemungkinan besar akan dipotong atau dikurangkan kerana kos yang tinggi. Perkongsian empat syarikat produksi ini turut memperlihatkan bahawa kos pembikinan filem ini menggunakan perbelanjaan yang besar. Walaupun terdapat akta atau undang-undang seperti seksyen 19 (1) Akta Kerja 1955 (Kementerian Sumber Manusia, 2021) yang menyatakan pembayaran gaji perlu dilakukan pada minggu pertama setiap bulan, penguatkuasaannya masih dilihat tidak melindungi pekerja yang seringkali menerima gaji lewat. Malah, amaran denda RM10,000 untuk kelewatan pembayaran gaji pekerja turut 
tidak diendahkan. Banyak pekerja filem yang dibayar gajinya selepas berbulan-bulan tamat bekerja dalam sesebuah produksi. Pelakon Risteena Munim, misalnya bekerja selama dua bulan tanpa bayaran pada tahun 2017 dan tiada berita lanjut yang mengatakan bahawa isu ini telah selesai (Raja Nurfatimah, 2017). Perkara ini tidak sepatutnya berlaku kerana melanggar Akta Kerja 1955.

Kebajikan pekerja filem sering diabaikan oleh pihak majikan dan pihak berkuasa. Pelakon Ben Ali menegaskan bahawa kebajikan pekerja industri perfileman yang banyak membantu pembangunan industri telah lama dilupakan dan mereka hanya menerima kadar bayaran yang rendah, bekerja lebih masa, tiada jaminan masa hadapan, sukar membuat pinjaman bank dan sebagainya (Rafiq, 2018). Terdapat juga pekerja filem yang melakukan protes secara senyap dengan menyepikan diri dari dunia perfileman disebabkan kecewa dengan pembayaran gaji pekerja yang tidak setimpal. Sesetengah pelakon veteran seperti Khatijah Tan (2020) mengakui bahawa keadaan ini telah mendorong anaknya, iaitu Pierre Andre (pelakon dan pengarah filem) menyepikan diri dari dunia filem.

\section{ULASAN KAJIAN LEPAS DAN TEORI KAJIAN}

Terdapat segelintir kajian lepas yang berkaitan dengan isu bayaran pekerja filem di Malaysia meskipun amat kurang disentuh dan dibincangkan secara rinci. Kajian yang dilakukan oleh Abdul Razak dan Mohd Syuhaidi (2018) menekankan bahawa isu pembayaran pekerja filem adalah disebabkan syarikat produksi menghadapi kekurangan dana dan modal. Ini kerana segelintir pelabur dan peniaga menganggap industri perfileman kurang berpotensi untuk mengaut keuntungan besar menyebabkan mereka sukar untuk memberikan dana sehingga proses produksi terjejas dari peringkat praproduksi hingga pascaproduksi (Abdul Razak \& Mohd Syuhaidi, 2018).

Masalah ini boleh menyebabkan motivasi pekerja filem merosot. Menurut Abdul Razak dan Mohd Syuhaidi (2018) motivasi yang diberikan kepada pekerja seperti ganjaran, kenaikan gaji, peluang kenaikan pangkat dan keselesaan di tempat kerja biasanya akan mendorong pekerja filem rajin bekerja dan menghasilkan filem yang berkualiti. Mohd Adnan et al. (2011) menegaskan bahawa penggiat filem di Malaysia khususnya syarikat milik Bumiputera kebanyakannya tidak mempunyai sistem perancangan dan juga pentadbiran yang baik. Ini juga boleh menyebabkan masalah dari segi pembayaran gaji pekerja filem yang sepatutnya dilakukan secara sistematik dan menepati waktu. Tambahan pula, kebanyakan filem yang diterbitkan bergantung kepada dana kerajaan atau pinjaman bank yang menyebabkan produksi perlu dilakukan dalam tempoh "segera" dengan masa yang terhad. Ini demi mengelakkan pihak produksi menanggung kos yang tinggi kerana terpaksa menyewa peralatan, kru dan melantik pekerja sambilan.

Selain itu, terdapat penerbit filem yang mencari alternatif untuk mendapatkan dana bagi menyiapkan karya mereka dengan mencari orang awam yang berminat untuk melaburkan wang untuk tujuan pembiayaan produksi. Hanisah (2019) menyatakan bahawa tajaan berbentuk peletakan produk (product placement) oleh produksi Prokuya Studio menjadi tular di media sosial setelah dikongsi oleh orang awam dan penggiat-penggiat seni tanah air. Berita ini memberi gambaran buruk industri filem negara dalam kalangan orang awam. Sementara itu, Daeng Haliza dan Ab Samad (2011) melihat peranan persatuan-persatuan filem seperti SENIMAN, FDAM dan PROFIMA yang menjaga kebajikan ahli-ahlinya yang kebanyakannya 
terdiri daripada pekerja filem di Malaysia di samping memastikan pembangunan modal insan yang baik dan menggubal dasar perfileman Malaysia. Pada masa yang sama, Fatimah dan Nur Afifah (2020) meneliti peranan FINAS dan sumbangannya kepada pekerja filem yang merangkumi individu seperti sinematografer, penyunting, pereka produksi, pengarah seni, pengarah fotografi, props master, gaffer, grip dan foley artist. Secara umum, kumpulan tenaga kreatif ini memainkan peranan penting dalam menentukan kandungan identiti dan keaslian filem nasional Malaysia. Namun, kajian mereka tidak menyentuh tentang isu bayaran hasil kerja pekerja filem mahupun isu-isu persatuan filem.

Isu bayaran hasil kerja pekerja filem pernah dibincangkan oleh Hanisah (2020) yang menegaskan bahawa terdapat suara-suara pekerja filem yang tidak berpuas hati dengan upah yang dikenakan. Malahan mereka turut dipulaukan daripada mendapat pekerjaan dan berkemungkinan dibayar upah yang rendah. Hanisah (2020) menegaskan bahawa pelakon Jalil Hamid pernah meluahkan pendapat dalam media sosial mengenai bayaran yang diterimanya amat rendah walaupun memegang watak utama. Namun, kelantangannya itu menyebabkan beliau tidak mendapat sebarang tawaran berlakon selama tujuh bulan. Di sini dapat dinilai bahawa kebebasan suara pekerja filem sering disekat dan dibuli. Perkara ini membawa kepada penindasan kepada para pekerja filem dan tidak boleh dibahaskan kerana kuasa ekonomi terletak pada tangan golongan kapitalis seperti penerbit filem. Misalnya Azlina (2019) menyatakan bahawa Shakilla Khoriri (pelakon baharu) pernah mendapat tawaran lakonan dengan kadar bayaran rendah, iaitu sebanyak RM800 untuk penggambaran selama enam bulan pada awal pembinaan kerjaya beliau. Eksploitasi ini tidak terhad pada pelakon malah pekerja-pekerja filem yang lain seperti ketua juruteknik, jurukamera, penulis skrip, dan sebagainya.

Percival dan Hesmondhalgh (2014) telah menawarkan analisis yang sangat berguna mengenai pekerja tanpa gaji dalam sektor filem dan televisyen di United Kingdom. Hal ini berlaku disebabkan terdapatnya lebihan tenaga kerja dalam industri ini yang mendorong kewujudan penggunaan buruh tanpa gaji. Mereka menyatakan bahawa industri filem mempunyai tahap pekerjaan tanpa gaji yang lebih tinggi berbanding industri televisyen berdasarkan cara pengurusan dana yang diamalkan. Secara keseluruhannya, penerbitan televisyen tidak dihasilkan secara spekulatif; tetapi dihasilkan secara komersial oleh syarikat produksi profesional dan dibiayai oleh penyiar atau pengiklan.

Industri filem, walau bagaimanapun, mempunyai model pendanaan yang berbeza. Sebagai contoh, ada yang mendapat pembiayaan sebahagian untuk sebuah filem fiksyen daripada badan milik kerajaan tetapi hanya pekerja profesional dan kru tertentu sahaja yang dibayar upahnya. Bagi filem yang dikeluarkan oleh syarikat produksi amatur yang sedang bertapak dan mengembangkan kerjaya dalam industri filem dan tidak mendapat pembiayaan, mereka merekrut kru yang kurang berpengalaman yang berkhidmat secara percuma tetapi ditawarkan kredit pada filem yang dihasilkan. Kajian Percival dan Hesmondhalgh (2014) mendapati industri televisyen dan filem cenderung mengambil pekerja amatur tanpa gaji atau dibayar dengan gaji rendah untuk sebarang projek sedangkan kru lain yang berpengalaman mendapat penghargaan yang lebih baik. Kesannya, syarikat produksi berpotensi untuk menjana kewangan. Keadaan ini berlaku pada peringkat awal kerjaya pekerja filem yang biasanya berkorban menjadi buruh percuma. Kelihatan juga perbezaan sikap pekerja bebas amatur tanpa gaji dalam industri filem dan televisyen. Pekerja berpengalaman sentiasa memberi maklum balas negatif (kurang bertoleransi) terhadap pekerjaan yang tidak dibayar 
manakala pendatang baru dalam kedua-dua sektor ini lebih bersedia untuk menonjolkan faedah bekerja tanpa gaji.

Namun, Percival dan Hesmondhalgh (2014) mengesahkan bahawa pekerja di industri filem lebih bersedia menerima pekerjaan tanpa gaji berbanding pekerja industri televisyen. Tinjauan juga memperlihatkan ciri yang lebih menarik: mereka yang bekerja lebih lama di kedua-dua sektor ini dilihat tidak dibayar gaji jauh lebih rendah daripada pekerja baharu. Kajian ini mendapati bahawa pekerja filem lebih banyak bertoleransi untuk pengalaman kerja yang tidak dibayar gaji berbanding dengan pekerja televisyen. Tinjauan yang dilakukan oleh majalah Broadcast terhadap 1071 pekerja bebas di United Kingdom pada tahun 2005 melaporkan bahawa 75\% responden telah berpengalaman kerja tanpa gaji- satu penjimatan kepada majikan sebanyak £28 juta (Strauss, 2005). Tinjauan yang dilakukan pada tahun 2012 pula mendapati $43 \%$ pekerja bebas menyatakan mereka telah bekerja percuma atau di bawah kadar standard sejak lima tahun lepas, dengan janji gaji akan dibayar kemudian-dengan 61\% kes tidak pernah berlaku (Neilan, 2012).

Percival dan Hesmondhalgh (2014) juga meneroka beberapa implikasi terhadap pekerja filem yang tidak dibayar gaji. Pekerjaan yang menawarkan khidmat percuma telah merendahkan nilai profesionalisme pekerja filem. Malahan, keadaan ini merosakkan kerjaya mereka yang bergantung pada industri perfileman untuk mencari nafkah serta boleh memberi kesan negatif terhadap kualiti pengeluaran industri kreatif. Selain Percival dan Hesmondhalgh (2014), terdapat juga kajian berkaitan dengan buruh yang tidak dibayar dalam industri budaya di United Kingdom (Banks 2017; Ashton 2016; Figiel 2013; Frenette 2013; Siebert \& Wilson 2013; Rolston \& Herrera 2000). Berbanding di Amerika Syarikat, syarikat produksi filem di United Kingdom mempunyai cara pembayaran gaji pekerja filem yang lebih sistematik. Hal ini diakui oleh Paul dan Kleingartner (1994) yang mengenal pasti perkembangan skim bayaran tiga peringkat dalam industri produksi filem dan televisyen di United Kingdom.

Selain itu, mereka menunjukkan penyelesaian tambahan untuk masalah yang tidak dijangka secara umum mengubah hubungan buruh dengan hubungan institusi utama iaitu syarikat produksi. Paul dan Kleingartner (1994) berpendapat bahawa transformasi yang mendasari hubungan pekerja filem tidak perlu datang dari perancangan strategik pada peringkat atasan. Tindakan tertentu boleh dilakukan pada peringkat bawahan seperti persatuan-persatuan pekerja filem yang dominan. Paul dan Kleingartner (1994) mengkaji tiga persatuan buruh profesional yang terlibat di dalam industri filem dan televisyen di Amerika Syarikat iaitu Screen Actors Guild (SAG), Writers Guild of America (WGA) dan Directors Guild of America (DGA). Ketiga-tiga persatuan ini mengembangkan institusi filem melalui penambahan keahlian dan tawar-menawar yang berkesan. Semua persatuan ini sentiasa berganding bahu walaupun terdapat perubahan teknologi produksi dan persaingan yang sangat kompetitif yang merendahkan pendirian mereka. Persatuan-persatuan ini terlibat dalam fungsi pengurusan tanpa terlibat secara langsung dalam membuat keputusan mengenai kontrak pekerjaan. Mereka mewakili golongan pekerja filem dengan mengambil berat tentang pembayaran gaji pekerja seperti pendapatan berbaki (residual income).

Bagi Paul dan Kleingartner (1996), pendapatan berbaki adalah bahagian penting dalam politik ekonomi berbilang tingkat bagi buruh pelakon di Hollywood. Pendapatan berbaki adalah hasil yang diperolehi setelah kerja yang dilakukan itu selesai tetapi sentiasa ada duit mengalir masuk. Contohnya, royalti tayangan filem dan royalti hasil penulisan skrip. 
Dengan ini, pekerja filem mendapat hak untuk berkongsi keuntungan. Menurut Paul dan Kleingartner (1996) lagi, penerimaan kontrak oleh pekerja filem mengenai pendapatan berbaki dalam dunia pekerjaan filem adalah konsesi yang belum pernah terjadi sebelumnya. Pelakon Screen Actors Guild (SAG) yang memberikan persembahan dalam filem dan televisyen layak untuk menerima bayaran pendapatan berbaki yang standard. Namun kelayakan ini hanya menepati syarat yang ditentukan dalam kontrak mereka iaitu bekerja "melebihi garis ketetapan" ("kreatif") dan bukannya "di bawah garis ketetapan" ("teknikal") (Paul \& Kleingartner 1994: 666). Isu bayaran pekerja filem boleh membawa kepada protes pekerja filem kerana hak keadilan dalam pekerjaan. Kajian ini menunjukkan bahawa penyelidikan dan pendidikan dapat mendorong pemahaman yang lebih baik mengenai nasib pekerja filem dan mengurangkan bilangan buruh tanpa gaji.

Kajian ini menggunakan Teori Pengasingan Marx (Marxist Theory of Alienation). Karl Marx menggunakan istilah Entfremdung (pengasingan), iaitu "Teori Pengasingan" yang menggambarkan pemisahan atau pengasingan makhluk atau sesuatu yang secara semula jadi disatukan (Marx, 1975). Secara konseptual dan etimologi, Entfremdung menggambarkan keadaan keterasingan dalam urusan sosial misalnya pengasingan masyarakat daripada prospek sifat semula jadi manusia hasil kehidupan berasaskan kelas atau masyarakat berstrata (Marx, 1975). Dalam masyarakat kapitalis yang dihuraikannya, pekerja cenderung menjual kekuasaan, kekuatan, kepakaran dan kemahiran mereka kepada kapitalis. Kesannya, pekerja tidak mempunyai kawalan terhadap produk buruh mereka. Oleh itu, mereka terasing dan menjadi mangsa pengasingan. Ini menyebabkan pekerja menjadi terasing daripada diri mereka sendiri, sifat mereka sendiri dan juga terasing daripada manusia lain dan juga dari pekerjaan mereka (Callinicos, 2004). Kesannya, dua kelas terbentuk, iaitu kelas Pekerja dan Kelas Kapitalis. Kelas Pekerja bekerja dan terasing manakala kelas Kapitalis adalah bukan pekerja tetapi mengawal pekerja dan mendapat keuntungan daripada tenaga kerja orang lain.

Marx (1959) dalam kajian klasik beliau, The Economic and Philosophic Manuscripts menerangkan cara kelas pekerja dieksploitasi oleh kapitalis dengan menggunakan kaedah produksi berdasarkan kapitalisme yang menguntungkan mereka dan pada masa yang sama mengeksploitasi pekerja. Disebabkan eksploitasi ini, golongan Kapitalis dan Pekerja adalah terasing. Beliau menganggap proses dan kejadian itu sebagai Pengasingan dari segi sosial. Ini bererti orang yang bersungguh-sungguh dalam pekerjaan hanya mendapat sedikit pulangan. Ini menyebabkan berlakunya konflik kelas dan perpecahan antara kedua-dua pihak iaitu penerbit dan pekerja filem. Justeru, Marx mendakwa bahawa di bawah pemerintahan kapitalis atau dalam masyarakat kapitalisme, pekerja dan kelas pekerja menjadi terasing. Pengasingan ini merangkumi pelbagai dimensi dan semua bidang kehidupan—agama, politik, hubungan sosial dan ekonomi - tetapi memberi kesan terutamanya dalam pekerjaan (Sayers, 2011).

Menurut Cox (1998), produk buruh adalah keadaan yang mana para pekerja terasing daripada objek yang merupakan hasil kerja mereka sendiri kerana golongan kapitalis memiliki hak ke atas objek tersebut. Jika dikaitkan dengan industri perfileman Malaysia, para pekerja filem tidak mendapat sebarang keuntungan royalti melalui hasil kerja mereka disebabkan filem itu bukanlah milik pekerja filem. Pekerja dibayar gaji minimum dan hasil pendapatan daripada hasil kerjanya adalah rendah. Ini terjadi kerana berlakunya eksploitasi terhadap golongan pekerja ("Communication Theory", n.d.). Jika dikaitkan dengan industri perfileman, kadar upah adalah rendah dan tidak berubah sejak dekad 1990-an lagi dan kadang-kala dibayar pada kadar minimum. Para pekerja juga tidak mempunyai kuasa dalam 
penentuan proses produksi kerana syarat kerja dan pengurusan dikawal oleh golongan kaya tanpa mempertimbangkan golongan pekerja secara individu ("Communication Theory", n.d.). Para pekerja hanya boleh berkarya mengikut kehendak pengeluar filem dan tidak ada kuasa penentu kepada proses produksi seperti bajet, prosedur bayaran, dan pembahagian keuntungan. Armando (2017) menerangkan bahawa golongan pekerja terasing daripada masyarakat. Perkara ini jelas kelihatan kerana mereka terpaksa menghabiskan masa untuk menyiapkan tugasan produksi yang mengambil hampir 24 jam sehari. Armando (2017) menegaskan bahawa Teori Pengasingan Marx menekankan keadaan para pekerja yang boleh menjadi terasing daripada intipati kemanusiaan. Para pekerja menjadi seseorang yang hilang sifat kemanusiaan kerana desakan dan tekanan kerja. Malahan, karya yag dihasilkan tidak mempunyai jiwa.

\section{KAEDAH KAJIAN}

Kajian ini menggunakan kaedah kualitatif dengan menggunakan pendekatan temu bual secara mendalam melalui mesej teks, iaitu temu bual melalui mesej dengan aplikasi WhatsApp disebabkan kekangan pandemik COVID-19 semasa Perintah Kawalan Pergerakan (PKP) di Malaysia. Kaufmann (2019) menerangkan bahawa penggunaan kaedah temu bual secara mendalam melalui aplikasi WhatsApp mampu memberi pemahaman yang lebih baik dan fleksibiliti dalam kajian kerana mampu merentasi sempadan masa dan kawasan dan hasilnya masih relevan untuk diguna pakai dalam kajian penyelidikan akademik. Oleh itu, penggunaan teknologi ini telah dikaji keberkesanannya untuk tujuan penyelidikan akademik dan boleh diterima secara global melalui kajian dengan menggunakan pendekatan kualitatif, iaitu temu bual secara mendalam.

Schober et al (2015) menjelaskan bahawa kaedah temu bual melalui mesej teks dengan menggunakan telefon pintar diterima oleh Lembaga Institusi Pengajian Semula Sains Kesihatan dan Sains Tingkah Laku dari University of Michigan dan Lembaga Institusi Pengajian Semula dari The New School. Kaedah ini juga diperakui dalam bidang berkaitan Sains Tingkah Laku dan Sains Kesihatan. Skop kajian ini melibatkan penggiat seni filem dalam industri perfileman di Malaysia. Sesi temu bual dijalankan mengikut jadual dan perancangan yang ditetapkan, iaitu dari Februari hingga Jun 2020 dan Mac 2021.

Kesemua informan adalah pekerja bebas yang mempunyai pengalaman kerja selama 6 hingga 31 tahun. Pengalaman kerja informan memberi impak yang signifikan terhadap kajian kerana informan yang mempunyai lebih banyak pengalaman dalam industri filem mempunyai lebih banyak pendedahan dan pemahaman mengenai masalah pembayaran. Ini meningkatkan kebolehpercayaan dan kesahan penemuan untuk kajian ini.

Informan yang terpilih juga telah bekerja dengan pelbagai syarikat perfileman dan telah menyiapkan lebih daripada tiga projek. Ini menunjukkan bahawa sebahagian besar informan mempunyai pengalaman yang baik berdasarkan jumlah projek yang disiapkan, yang menggambarkan pengalaman mereka terhadap masalah pembayaran yang meningkatkan kebolehpercayaan data yang dikumpulkan. Informan-informan terbabit merupakan Pengarah Seni, Pengarah Fotografi, Pengarah Muzik, Pereka Produksi, Pengurus Produksi dan ahli persatuan filem. 


\section{DAPATAN KAJIAN}

Dapatan kajian hasil temu bual dibahagikan kepada dua bahagian, iaitu faktor masalah pembayaran gaji atau upah dan cara penyelesaiannya.

\section{Faktor Masalah Pembayaran Upah}

Berdasarkan maklum balas informan, masalah pembayaran pekerja filem di Malaysia didorong oleh faktor-faktor berikut yang sangat berkait dengan Teori Pengasingan oleh Marx. Teori ini antara lain menerangkan tentang penindasan terhadap golongan pekerja oleh golongan kapitalis. Misalnya, kebanyakan pekerja produksi ditindas dari segi bayaran dan hasil kerja.

\section{Ketidakjelasan perjanjian kerja dan perjanjian yang berat sebelah}

Isu bayaran projek timbul disebabkan perjanjian yang tidak kukuh antara majikan dengan pekerja filem. Terdapat terma perjanjian kerja, jenis pekerjaan yang dilakukan dan cara pembayaran yang tidak dinyatakan dengan jelas. Terdapat pekerja filem yang ditawarkan jawatan bergaji rendah tetapi dinyatakan berjawatan bergaji tinggi dalam ruangan penghargaan pada filem yang ditayangkan. Perjanjian berat sebelah pekerjaan dalam sesebuah produksi filem adalah antara isu utama dalam sektor industri filem Malaysia. Ini kerana perjanjian banyak berpihak pada pengeluar filem dan dalam kebanyakan hal pekerja terpaksa menerima terma dan syarat yang dinyatakan dalam surat perjanjian. Selain itu, pekerja terpaksa menerimanya tanpa soal kerana mereka amat memerlukan pekerjaan yang ditawarkan demi meneruskan kelangsungan hidup.

"Banyak syarikat produksi yang beri perjanjian yang tak jelas dan para pekerja filem terpaksa menandatangani begitu sahaja disebabkan kesempitan kerja. Ada yang offer bekerja sebagai Prop Master, tetapi, apabila drama keluar namanya pada credit tittle diletakkan sebagai Pengarah Seni...Perjanjian itu lebih berpihak kepada pihak pengeluar filem kerana kontrak dikeluarkan oleh mereka. Kita yang bekerja di bawahnya terpaksa terima seadanya."

(Informan 4, Pereka Produksi, Kuala Lumpur)

Masalah pembayaran juga berlaku disebabkan tiada prosedur standard dalam sistem pembayaran gaji pekerja filem di Malaysia. Ini disebabkan kurangnya pihak yang mengambil berat tentang kebajikan pekerja filem seperti pihak Perbadanan Filem Nasional Malaysia (FINAS) dan persatuan-persatuan penggiat filem. Tambahan pula kurangnya pengetahuan umum terhadap kerjaya perfileman. Hasil kerja pekerja filem juga sukar diukur kerana melibatkan kreativiti yang sangat subjektif.

“Dalam industri ini juga tidak mempunyai satu standard yang boleh dirujuk atas perkara pembayaran. Kepakaran dan sumbangan penggiat-penggiat filem adalah sesuatu yang subjektif dan ia susah diukur."

(Informan 3, Pengarah Muzik, Kuala Lumpur) 
Ketidakjelasan perjanjian kerja, perjanjian yang berat sebelah dan ketiadaan prosedur standard dalam profesionalisme perfileman ini menjadi punca kewangan pekerja filem terjejas. Hal ini selaras dengan sorotan literatur (Bound, et al., 2013) yang dinyatakan yang mana terdapat pekerja yang tidak mendapat bayaran setimpal dengan kerja, malahan ada yang tidak dibayar. Ini merupakan penganiayaan kepada hasil titik peluh pekerja dan menyebabkan sebelah pihak kerugian.

\section{Tahap literasi pekerja filem yang rendah}

Maklum balas temu bual mendapati bahawa tahap pemahaman pekerja-pekerja filem mengenai isu dalam pembayaran hasil kerja bagi sesebuah projek adalah rendah walaupun sudah diberi penerangan oleh pihak pengurus produksi sesebuah projek. Kebanyakan pekerja filem mengetahui perkara ini secara dasar sahaja dan tidak dapat mendalaminya. Ini disebabkan ramai pekerja filem tidak mendapat pendidikan tinggi dan tidak menjalani kursus kemahiran perfileman secara formal. Terdapat juga pekerja yang tidak meneliti perjanjian yang ditandatangani dan tidak mengambil berat tentang perkara ini.

"Tahap pemahaman penggiat-penggiat seni filem mengenai pembayaran kebanyakannya adalah rendah kerana ramai yang tidak meneliti kontrak tawaran pekerjaan filem dengan mendalam....Penerangan oleh pengurus produksi sering diberikan. Namun, terdapat para pekerja filem yang tidak cakna akan penerangan itu disebabkan faktor pendidikan dan sikap tidak ambil berat pekerja tentang sesuatu itu."

(Informan 4, Pereka Produksi, Kuala Lumpur)

"Antara golongan penggiat amat memerlukan satu persatuan yang telah ditubuhkan iaitu PROFIMA (Persatuan Pekerja Profesional Filem Malaysia) untuk mencuba menyelesaikan masalah ini. Selama ini, dapat didengari bahawa persatuan ini masih bekerja keras untuk menyelesaikan isu ini. Tetapi, belum nampak ada pencapaian yang memuaskan."

(Informan 2, Pengarah Fotografi, Kuala Lumpur)

"Sememangnya isu bayaran pekerja filem menyebabkan pekerja filem hidup susah kerana ... tiada tindakan daripada pihak persatuan-persatuan...Persatuan filem kurang sangat [kompeten] kerana dikendalikan oleh peniaga filem sendiri. Persatuan sepatutnya diwakili oleh pekerja dan bukan peniaga filem."

(Informan 4, Pereka Produksi, Kuala Lumpur)

"Persatuan filem sememangnya tidak berfungsi sejak 28 tahun yang lalu."

(Informan 6, Ahli Persatuan Filem, Kuala Lumpur)

Persatuan-persatuan pekerja dan penggiat filem memainkan peranan yang penting dalam memastikan kebajikan pekerja filem. Pembayaran gaji pekerja filem sepatutnya lebih terjamin melalui persatuan ini yang membantu dalam menyuarakan isu berkaitan pekerja filem. Walau bagaimanapun, di Malaysia persatuan penggiat filem tidak kompeten dan masih goyah 
dalam menangani isu-isu yang timbul dalam dunia perfileman Malaysia. Banyak isu pekerja filem telah disuarakan kepada persatuan, tetapi hasilnya tidak memuaskan pekerja filem. Contohnya, waktu bekerja wanita dan kanak-kanak pada waktu malam yang sepatutnya tidak berlaku, waktu kerja lebih masa dan bayaran yang tidak setimpal dengan kerja yang dilakukan masih belum dapat diselesaikan. Persatuan yang sepatutnya mewakili pekerja dan penggiat seni filem gagal menangani kebanyakan masalah ahli-ahlinya kerana ada persatuan yang dikendalikan oleh peniaga filem sendiri yang mempunyai kepentingan komersial.

\section{Aliran Tunai yang Terhad}

Faktor terakhir kepada masalah pembayaran dalam kalangan pekerja filem adalah disebabkan oleh aliran tunai yang tidak mencukupi. Ini disebabkan kos produksi meningkat dan filemfilem yang dijual ke stesen televisyen masih tidak meningkat harganya. Ini menyebabkan aliran tunai pihak penerbit tidak mencukupi untuk meneruskan produksi dan menjejaskan bayaran kepada pekerja filem. Dalam kalangan pekerja filem, pelakon lebih diutamakan daripada segi pembayaran.

"Sudah lebih 20 tahun dan tidak ada kenaikan bayaran pembelian produk oleh
stesen televisyen. Sedangkan segala keperluan produksi sudah naik harga seperti
sewa lokasi, sewa prop, petrol, sewa tempat penginapan, makan dan minum, dan
bayaran artis. Namun, bayaran kru tidak naik kerana terpaksa bayar lebih kepada
pelakon."

(Informan 6, Ahli Persatuan Filem, Kuala Lumpur)

Berkaitan dengan aliran tunai yang tidak mencukupi ini, terdapat desakan agar pihak pengeluar filem mengurangkan pembiayaan yang diperoleh untuk filem itu secara drastik. Pengurangan drastik terhadap bajet produksi yang dilakukan oleh syarikat produksi filem menyebabkan para pekerja terhimpit. Ini menampakkan bahawa isunya timbul daripada pihak syarikat itu sendiri yang menginginkan perbelanjaan yang rendah agar mereka boleh mengaut keuntungan yang lebih tinggi. Perkara ini menjadi masalah kepada para pekerja filem itu sendiri apabila mereka terpaksa bekerja dengan bayaran yang tidak setimpal atau tiada sebarang pembayaran langsung.

"...bila sesuatu jabatan memberi bajet untuk bekerja tetapi unit produksi memotong bajet yang diperuntukkan dengan alasan bajet tidak mencukupi."

(Informan 1, Pengarah Seni, Kuala Lumpur)

Pengurangan pembiayaan untuk sesuatu projek secara drastik mencerminkan sesebuah syarikat produksi filem tidak mempunyai aliran tunai yang mencukupi. Tekanan ini harus ditanggung oleh pekerja filem sehingga kadangkala pekerja terpaksa berkorban masa dan wang ringgit untuk meneruskan projek sehingga selesai demi menjaga reputasinya yang kebanyakannya pekerja sambilan seperti menanggung duit tambang perjalanan, duit minyak, duit belanja dan sebagainya yang memberi tekanan kepada kehidupan mereka. 


\title{
Masalah Pembayaran Gaji Pekerja Filem
}

Syarikat yang menghadapi masalah kewangan seringkali melalukan pembayaran gaji yang lewat atau secara ansuran kepada pekerja filem.. Masalah berkaitan gaji ini akhirnya membawa kesan negatif dalam industri filem dan juga kepada individu terbabit dan ini selari dengan hasil dapatan kajian Percival dan Hesmondhalgh (2014) dan Abdul Razak dan Mohd Syuhaidi (2018). Individu yang terlibat sudah pasti bakal berhadapan dengan bebanan kewangan lain sehingga ada yang hidup susah dan tidak mampu untuk memajukan diri di samping tidak mencapai kepuasan dan matlamat hidup juga kerjaya kebanyakan informan yang ditemui bersetuju bahawa masalah pembayaran ini menyebabkan mereka terjerat dengan beban kewangan peribadi. Kadangkala, pekerja filem perlu mengeluarkan duit sendiri walaupun bekerja melebihi masa supaya projek yang dilaksanakan dapat diselesaikan untuk membolehkan mereka mendapat kontrak pekerjaan seterusnya.

\begin{abstract}
"Kalau perbincangan berkaitan dengan isu bayaran gaji, ia betul menyebabkan penggiat filem atau kru filem hidup dalam kesusahan kerana dengan bayaran rendah kami harus mengeluarkan duit sendiri untuk bayar minyak, makanan, dan barangan lain untuk menjayakan filem tersebut."
\end{abstract}

(Informan 1, Pengarah Seni, Kuala Lumpur)

"Produser-produser tidak mengendahkan permintaan para pekerja filem sehingga menyebabkan para pekerja filem menjadi susah dan tidak mendapat bayaran setimpal apatah lagi lumayan untuk menyara kehidupan seharian mereka."

\section{(Informan 5, Pengurus Produksi, Kuala Lumpur)}

Amalan pembayaran lewat dalam industri filem Malaysia mula menjadi norma dan kebiasaan bagi mereka yang terlibat di dalam bidang ini. Sejajar dengan Teori Pengasingan Marx, golongan pekerja filem ini adalah mereka yang menghasilkan karya filem untuk kekayaan golongan kapitalis (yakni pengeluar filem). Pada akhirnya, kekayaan yang dicipta oleh pekerja itu telah diambil dan dimiliki oleh kapitalis. Oleh itu, buruh upah yakni pekerja filem dan kekayaan yang diciptanya telah menjadi sesuatu yang asing dan terpisah daripada pekerja itu. Inilah yang dimaksudkan oleh Marx sebagai "pengasingan buruh".

Pengasingan membawa maksud sesuatu yang dicipta seseorang telah terpisah daripada pencipta itu sendiri, pekerjaan itu bukan lagi tidak dapat dikawal olehnya, tetapi bertukar menjadi kuasa asing yang bertentangan dengannya dan menghambakannya. Maka, pekerja filem akhirnya dikuasai oleh kapitalis. Dalam proses penerbitan industri filem di bawah sistem kapitalis, pekerja filem telah hilang kawalannya ke atas karyanya sendiri, maka hilanglah juga kawalannya terhadap kehidupannya. Pekerja filem itu bukan lagi seorang yang manusia yang bebas, malah dia hanya wujud mengikut bentuk yang dikehendaki oleh sistem kapitalis dan kelas kapitalis yang mendominasinya. Kelas kapitalis ini bukan sahaja menguasai buruh pekerja dengan membeli tenaga kerja melalui upah, tetapi juga menguasai karyawan filem yang mencipta produk itu (yakni filem), supaya dapat membentuk cita rasa penonton (pengguna) untuk menonton (membeli) produk itu dengan tujuan memaksimunkan keuntungan. Produk yang dihasilkan oleh pekerja filem itu dimiliki sepenuhnya oleh kapitalis, bukannya pekerja. Begitu juga segala keuntungan yang dijana oleh produk hasilan pekerja 
itu dinikmati sepenuhnya oleh kapitalis, bukannya pekerja filem. Malahan, sekiranya, produk yang dihasilkan pekerja filem itu dibawa pulang ke rumah atau dimuat turun tanpa kebenaran, maka pekerja yang merupakan karyawan asal produk itu boleh disabitkan dengan kesalahan merompak.

\title{
Penyelesaian Isu Bayaran Pekerja Filem di Malaysia
}

Isu bayaran pekerja filem perlu diselesaikan. Hasil kajian juga bertepatan dengan sorotan literatur yang dilakukan iaitu penyelesaiannya masih banyak perlu ditambah baik kerana undang-undang yang masih longgar dalam menangani isu ini. Hasil temu bual yang dijalankan, mendapati bahawa isu bayaran pekerja filem boleh diselesaikan.

\section{Kejelasan kesefahaman pekerja dan penerbit filem}

Isu bayaran adalah berkait dengan pengurusan dan perjanjian pekerjaan di antara pihak pekerja dan majikan. Kedua-dua pihak perlu saling memahami dan bersetuju dengan kontrak penerimaan sesuatu kerja yang ditawarkan. Ketelusan, kejujuran dan amanah semua pihak dalam menguruskannya amat diperlukan. Pekerja perlu melakukan perbincangan dengan pengurusan tertinggi bagi mendapatkan maklumat seperti keadaan fizikal kewangan syarikat itu. Sekiranya aliran tunai syarikat terjejas dan tiada pelan yang konstruktif dalam menangani permasalahan tersebut, pekerja filem boleh membuat keputusan awal agar tidak terjebak dalam risiko yang lebih teruk.

“..Paling penting adalah komunikasi antara pihak-pihak yang berkenaan dan juga kontrak yang dipersetujui oleh kedua-dua belah pihak dan bagaimana kesemua pihak memegang kepada amanah untuk menghormati apa yang telah dipersetujui. Oleh itu, soal integriti juga penting. Setiap pihak harus jujur dalam isu ini untuk mengelakkan sebarang konflik....Perjanjian sepatutnya apa yang telah dibincangkan dan diterima oleh kedua-dua pihak. Maka harus ada perbincangan dan mutual understanding sebelum perjanjian disediakan."

(Informan 3, Pengarah Muzik, Kuala Lumpur)

"Perbincangan harus didengari oleh kedua-dua pihak agar sama-sama menang dan adil dalam membuat keputusan."

(Informan 6, Ahli Persatuan Filem, Kuala Lumpur)

\begin{abstract}
"Kefahaman dalam isu bayaran ada dalam kontrak dan setiap kontrak agak berlainan. Isu ini cuma ada masalah sekiranya produksi lambat bayar dan adakala tidak dibayar langsung. Kita dibayar mengikut kadar individu, jawatan dan pengalaman pekerja. Sebab itu kita kena ada kontrak dengan produksi dan perlu baca dengan teliti kontrak terbabit. Yang penting produksi bayar mengikut seperti dalam kontrak."
\end{abstract}

(Informan 4, Pereka Produksi, Kuala Lumpur)

Pekerja filem perlu juga memahami kontrak pekerjaan dan cara hasil kerja mereka dibayar oleh sesebuah produksi filem. Hasil temu bual dengan pekerja-pekerja filem mendapati 
bahawa mereka mengharapkan pekerja-pekerja filem dapat memahami cara pembayaran kerja mereka kerana setiap kontrak pekerjaan dalam sesebuah produksi filem adalah berbeza. Tambahan pula setiap produksi mempunyai pelbagai unit yang masing-masing memainkan peranan yang berbeza dan seharusnya mereka dibayar mengikut jenis tugasan yang dipikul dan pengalaman bekerja. Contohnya, dalam produksi filem Paskal, pengurus produksinya membacakan segala terma dan syarat dalam kontrak yang ditandatangani oleh pihak pekerja filem. Perkara ini adalah praktikal dan pengurus produksi seharusnya memastikan kesemua pekerja filem yang terlibat memahami kontrak.

\section{Pembayaran upah yang sistematik dan pemantauan persatuan perfileman}

Pihak penerbit filem mesti sediakan bayaran dengan cara sistematik dan adil berdasarkan pecahan bayaran yang dipersetujui oleh kedua-dua pihak. Ini disebabkan setiap produksi mempunyai cara yang berbeza dalam menyelesaikan pembayaran hasil kerja para pekerja filem yang berkhidmat dalam produksi mereka. Pembayaran boleh dilakukan melalui dua hingga empat peringkat. Misalnya, jika pembayaran tiga peringkat dilakukan, pembayaran pertama boleh dibayar sebanyak 40 peratus pada peringkat pra produksi, bayaran kedua, 30 peratus dibayar pada peringkat produksi dan bayaran baki, 30 peratus selepas produksi selesai. Tempoh pembayaran juga mestilah dilakukan dalam jangka waktu yang singkat dan bukannya memakan masa yang lama. Ini dibuktikan melalui temu bual dengan pekerjapekerja filem:

“..Secara kebiasaannya, pembayaran bermula dengan 10\% daripada gaji penuh setelah menandatangani kontrak dengan produksi, 40\% untuk bayaran kedua, $40 \%$ lagi untuk pembayaran yang ketiga dan akhirnya $10 \%$ pembayarannya adalah selepas dua minggu dari tarikh penggambaran berakhir."

(Informan 1, Pengarah Seni, Kuala Lumpur)

"Terma pembayaran terlalu lama...bayaran akhir sehingga dua bulan atau lebih, sepatutnya bayaran kena buat lebih awal."

(Informan 4, Pereka Produksi, Kuala Lumpur)

Berhubungan dengan itu, peranan persatuan-persatuan perfileman seperti PROFIMA, SENIMAN, FDAM dan lain-lain adalah amat penting untuk menyelesaikan masalah yang dihadapi oleh pekerja filem. Pekerja-pekerja filem memerlukan Persatuan untuk membantu mereka menuntut hak mereka, mengelakkan jumlah yang dihutang menjadi lebih besar, dan memberi peluang yang paling baik untuk mendapatkan semula gaji. Disebabkan tanggungjawab itu, maka persatuan pekerja filem seperti PROFIMA mestilah bertindak segera sekiranya berlaku sebarang isu dan pelanggaran hak pekerja. Tindakan segera ini juga mestilah disusuli dengan kesan yang memuaskan pekerja filem. 
“...sekiranya berlaku masalah pembayaran dan melanggar kontrak, PROFIMA mesti menyelesaikan masalah bagi kru-kru filem dan SENIMAN mesti membantu para pelakon. ...Persatuan filem kena sediakan peguam awam untuk bantu pekerja filem selesaikan isu."

(Informan 5, Pengurus Produksi, Kuala Lumpur).

“Peranan persatuan amat penting demi menjaga pekerja filem...Isu bayaran... masalah selalu terjadi bila bayaran lambat dan kekadang tak dibayar langsung. Jadi persatuan boleh bekerjasama dengan FINAS mengambil tindakan saman atau denda seperti bayar lebih tempoh yang sepatutnya dan FINAS boleh blacklist syarikat/produser filem."

(Informan 4, Pereka Produksi, Kuala Lumpur)

Persatuan-persatuan yang terlibat dengan filem mestilah berusaha memperjuangkan hak pekerja filem kerana isu ini melibatkan sumber manusia yang merupakan tulang belakang kepada industri filem. Dengan kecaknaan pihak majikan terhadap kebajikan hak pekerja, maka mereka boleh mengelakkan mogok pekerja dianjurkan dan sekali gus mengelakkan kerencatan penghasilan filem seperti yang pernah berlaku dalam industri televisyen Malaysia iaitu pergerakan Switch Off. Pergerakan Switch Off diadakan demi mewujudkan Akta Industri Kreatif, memberi penekanan terhadap isu hak harta intelek yang lebih adil dan munasabah, isu kadar harga, dan pelarasan harga belian kandungan televisyen dan pengagihan slot televisyen dengan lebih adil (Astro Awani, 2014).

\section{Undang-undang dan jaminan hak pekerja filem}

Untuk menjamin hak, kerjaya dan kehidupan pekerja-pekerja filem, undang-undang mestilah diperkukuhkan dengan menitik beratkan kebajikan pekerja. Tiada akta yang melindungi majikan yang menangguhkan pembayaran gaji pekerja. Sebagaimana hasil dapatan kajian ini, terdapat segelintir pekerja yang tidak dibayar gaji tepat pada masanya, dan ada pula yang tidak dibayar sama sekali. Menurut Akta Pekerjaan, ia adalah kewajipan majikan untuk membayar gaji pekerja mereka sekurang-kurangnya sebulan sekali dan dalam masa 7 hari selepas tamatnya tempoh gaji mereka. Aduan boleh dilakukan di Jabatan Tenaga Kerja dan failkan tuntutan di bawah Seksyen 69 Akta Penggajian 1955. Sekiranya tiada penyelesaian yang jelas, pekerja boleh membawa kes tersebut ke mahkamah. Begitu juga, pekerja filem boleh membuat aduan kepada FINAS atau persatuan pekerja filem atau membuat laporan polis sebelum memfailkan tuntutan ke mahkamah.

“...Para pekerja filem juga akan memaklumkan kepada Perbadanan Kemajuan Filem Nasional Malaysia (FINAS) untuk tindakan susulan....Jika tindakan ini tidak berhasil, laporan polis akan dibuat serta memfailkan tuntutan mahkamah."

\section{(Informan 5, Pengurus Produksi, Kuala Lumpur)}

"Biasanya dibawa kepada persatuan untuk diselesaikan masalah dan akhirnya di bawa kepada pihak peguam untuk diselesaikan di mahkamah jika tidak dapat diselesaikan di pihak persatuan. Perkara ini boleh selesai sekiranya penerbit mahu lakukan dan jika ada kenaikan 50\% dari harga sekarang bagi produk televisyen. 
Stesen televisyen harus menaikkan bayaran pembelian produk dari penerbitpenerbit sebanyak $50 \%$ jika ingin menyelesaikan isu bayaran tenaga kerja di belakang tabir."

(Informan 6, Ahli Persatuan Filem, Kuala Lumpur)

Seperti yang dimaklumkan oleh informan, harga jualan filem ke stesen televisyen tidak berubah sejak dua puluh tahun yang lalu. Bagi menangani masalah aliran tunai yang tidak mencukupi, stesen-stesen televisyen hendaklah meningkatkan bayaran jualan filem yang ditayangkan di televisyen. Syarikat televisyen yang membeli filem dengan harga yang tinggi akan memberi aliran tunai yang mencukupi kepada penerbit filem dan bayaran pekerja filem dapat dilunaskan pada masa yang ditetapkan. Dengan ini kebajikan pekerja filem dapat dijaga. Jelaslah, peranan badan-badan kerajaan, persatuan dan stesen televisyen dalam menangani isu bayaran pekerja filem amat penting demi meningkatkan profesionalisme perfileman Malaysia. Mereka seharusnya duduk bersama dan berbincang dengan lebih mendalam bagi mencapai persetujuan kepada kadar harga filem untuk tayangan televisyen agar pihak produksi mendapat keuntungan yang baik serta mampu memusingkan modal sekali gus membayar pekerja filem yang terlibat dengan bayaran yang setimpal dengan hasil kerja.

\section{KESIMPULAN}

Dapat disimpulkan bahawa pembayaran gaji pekerja filem adalah satu masalah yang sering berlegar dalam industri perfileman Malaysia dan memerlukan perhatian khusus oleh pihak berwajib. Melalui kajian ini dapat diketahui bahawa tiada prosedur yang sistematik dalam pembayaran pekerja filem yang mana pembayaran kebiasaannya dilakukan atas budi bicara pihak penerbit. Tahap pemahaman pekerja filem mengenai kontrak perjanjian dan pembayaran hasil kerja juga didapati adalah rendah yang mana masih ramai yang tidak memahami apa yang perlu dilakukan sekiranya pelanggaran kontrak berlaku. Jalan penyelesaian yang didapati melalui kajian ini membolehkan isu bayaran pekerja filem diselesaikan dengan sebaik mungkin seperti penyediaan peguam oleh setiap persatuanpersatuan filem agar dapat membantu menyelesaikan isu bayaran mengikut undang-undang, menyediakan prosedur operasi standard (SOP) yang baik berpandukan undang-undang bagi pembayaran hasil kerja pekerja filem, dan memastikan semua pihak memahami kontrak sebelum mempersetujui dan menandatanganinya agar tidak dibelenggu dengan isu bayaran.

Isu bayaran pekerja filem merupakan satu isu yang amat besar dan perlu diperhalusi oleh pelbagai pihak yang berkaitan seperti FINAS, Kementerian Komunikasi dan Multimedia (KKMM), persatuan-persatuan perfileman, dan para pekerja filem itu sendiri kerana ia merupakan tunjang kepada pembangunan dan perkembangan industri perfileman Malaysia. Sekiranya isu ini tidak dapat diselesaikan dengan baik, kemajuan industri perfileman akan terganggu yang mana kebarangkalian untuk para pekerja filem mogok adalah tinggi. Kajian ini berpotensi untuk membantu menyelesaikan isu ini dengan berfungsi sebagai pengenalan dan penyelesaian kepada isu bayaran hasil kerja pekerja filem untuk diteliti oleh pihak berwajib. 
Kajian ini menyumbang dalam mengkaji tahap pemahaman penggiat seni filem tanah air dalam isu berkaitan pembayaran hasil kerja mereka bagi membolehkan mereka mengambil langkah-langkah yang betul dalam menyelesaikan isu ini pada masa akan datang. Ini juga membolehkan kita mengetahui sama ada isu ini membelenggu kehidupan mereka dan mempengaruhi pemikiran dan tingkah laku mereka dalam pekerjaan sehingga menyebabkan golongan ini hidup susah atau tidak. Dengan ini pihak berwajib boleh merangka bantuan yang perlu diberikan kepada mereka dan tidak terhad kepada bantuan kewangan atau sokongan moral. Kajian ini dapat mengelakkan dan mengurangkan penindasan kepada para pekerja filem itu sekali gus memantapkan hasil karya industri perfileman di Malaysia.

\section{RUJUKAN}

Abdul Razak Haja Mohaideen, \& Mohd Syuhaidi Abu Bakar. (2018). Meneroka permasalahan tenaga modal insan dalam industri filem di Malaysia. Forum Komunikasi, 13(1), 41-56.

Ab Samad Kechot, \& Daeng Haliza Daeng Jamal. (2011). Non-government organisation (NGO): Role NGOs film in malaysia for literature. Journal of Techno-Social, 3(1), 79-102.

Amirul Haswendy Ashari. (2018, Januari 22). Dapat dana juta-juta, shuhaimi kesal kru tak dibayar. myMetro. https://www.hmetro.com.my/utama/2018/01/306132/dapat-dana-jutajuta-shuhaimi-kesal-kru-tak-dibayar

Armando. (2017). Marx's Conception of Alienation. Dicapai daripada https://demoskratia.org/ marxs-conception-of-alienation-7e9d47b78220

Ashton, D. (2016). Creative contexts: work placement subjectivities for the creative industries. British Journal of Sociology of Education 37 (2), 268-287.

Banks, M. 2017. Creative justice: cultural industries, work and inequality. London: Rowman \& Littlefield.

BERNAMA. (2019, Februari 20). Rombakan FINAS perkasakan industri filem negara - Gobind. Berita Harian Online. https://www.bharian.com.my/berita/nasional/2019/02/533177/ rombakan finas-perkasakan-industri-filem-negara-gobind

Bound, H., Rushbrook, P., Waite, E., Evans, K., Lin, M., Karmel, A., Nur, S., Sivalingam, M., \& Seng, A. (2013). The entrepreneurial self: Becoming a freelancer in Singapore's Film and Television Industry. Singaore: Institute for Adult Learning (IAL).

Communication Theory. (n.d.). Marxist Theory of Alienation. Dicapai daripada https://www. communicationtheory.org/marxist-theory-of-alienation/

Callinicos, A. (2004). The revolutionary ideas of Karl Marx. Sydney: The Bookmark Publications.

Cox, J. (1998). An introduction to Marx's Theory of Alienation. http://pubs.socialistreviewindex. org.uk/isj79/cox.htm

[DIKN] Dasar Industri Kreatif Negara. (2013). Kementerian Penerangan Komunikasi dan Kebudayaan. Dicapai daripada https://www.kkmm.gov.my/pdf/Dasar/dikn.pdf

Daeng Haliza Daeng Jamal \& Ab Samad Kechot. (2011). Peranan badan bukan kerajaan (NGO) perfileman. Jurnal Melayu, (6), 87-104

Dex, S., Willis, J., Paterson, R., \& Sheppard, E. (2000). Freelance workers and contract uncertainty: the effects of contractual changes in the television industry. Work, Employment and Society, 14(2), 283-305. 
Figiel, J. (2013). Work experience without qualities? A documentary and critical account of an internship. Ephemera 13 (1): 33-52.

Frenette, A. (2013). Making the intern economy: role and career challenges of the music industry intern. Work and Occupations 40 (4), 364-397.

Hanisah Selamat. (2019, 30 Disember). Minta 'sponsor' pun jadi isu - Yana Samsudin. Berita Harian Online. https://www.bharian.com.my/hiburan/selebriti/2019/12/642678/mintasponsor-pun-jadi-isu-yana-samsudin

Hanisah Selamat. (2019, Ogos 26). KWSP, PERKESO untuk penggiat seni dilaksana mulai 1 Januari. Berita Harian Online. https://www.bharian.com.my/hiburan/lainlain/2019/08/600195/kwsp-perkeso-untuk-penggiat-seni-dilaksana-bermula-1-januari

Hanisah Selamat. (2019, 28 November). Kita selesaikan satu persatu - Hans Isaac. Berita Harian Online. https://www.bharian.com.my/hiburan/lain-lain/2019/11/632932/kitaselesaikan-satu-persatu-hans-isaac

Hanisah Selamat. (2020, Januari 6).). Ramai sentap bila saya tegur. Berita Harian Online. https:// www.bharian.com.my/hiburan/selebriti/2020/01/644347/ramai-sentap-bila-saya-tegur

Haris Hauzah. (2019, November 26).). Sebelum FINAS dilanda malang ganda lima. Malaysiakini Dicapai daripada https://www.malaysiakini.com/hiburan/501242

Haris Hauzah. (2019, September 5). Meratapi nasib pekerja filem yang masih 'terjajah'. Malaysiakini Dicapai daripada https://www.malaysiakini.com/hiburan/490731

Hasrul Hashim, Jamaludddin Aziz, \& Faridah Ibrahim. (2014). Filem dan revolusi teknologi: Persepsi penggunaan CGI dari aspek estetik \& kreativiti. Jurnal Komunikasi, 30(1), 104-105.

Hazlin Falina Rosli, Safura Ahmad Sabri, Norazla Abdul Wahab, \& Nurzakira Afnee Zakaria. (2015). Kesedaran golongan majikan terhadap orang kurang upaya (OKU) di Malaysia: Melalui perspektif media. Jurnal Pengurusan dan Muamalah, 2 (1), 198-199.

Hidayah Hairom. (2019). Isu RM1 bilion: Kerajaan tuntut bayaran projek belum dilaksana: Tun Mahathir. Sinar Harian. https://www.sinarharian.com.my/article/37976/BERITA/ Nasional/Isu-RM1-bilion Kerajaan-tuntut-bayaran-projek-belum-dilaksana-Tun-M Jamil Sulong. (2007). Warisan dan wawasan. Kuala Lumpur: Dewan Bahasa dan Pustaka. Joseph. G. (2020, 24 Jan). Bajet rendah filem 'mahal' . myMetro. https://www.hmetro.com.my/ rap/2020/01/538020/bajet-rendah-filem-mahal

Ikmal Hisham Md Tah. (2014). Orang kurang upaya (OKU) dan hak untuk hidup: Satu analisis perundangan di Malaysia. Jurnal Undang-undang, Polisi dan Keadilan Sosial, 1(1), 1-9.

Kaufmann, K. (2019). The mobile instant messaging interview (MIMI): Using Whatsapp to enhance self-reporting and explore media usage in situ. Mobile Media E Communication 8 (2), 229-246.

Kemalia Othman (2010, Februari 9). Hairie buat laporan polis produksi tak bayar gaji. mStar Dicapai daripada https://www.mstar.com.my/spotlight/hiburan/2010/02/09/hairie-buatllaporan-polis-produksi-tak-bayar-gaji

Kementerian Sumber Manusia. (2021) Akta Kerja, 38 M.C. § 265 (1955).Dicapai daripada http://www.mp.gov.my/acts/EA1955.pdf

Kementerian Dalam Negeri. (2021). Akta Penapisan Filem, 620 M.C. § 7 (2002). Dicapai daripada http://lpf.moha.gov.my/lpf/images/Perundangan/AKTA-PENAPISAN-FILEM. pdf 
Kool FM. (2019). Delimawati sedih pelakon senior hidup susah di hujung nyawa. Kool.fm. https:// www.koolfm.com.my/delimawati-sedih-pelakon-senior-hidup-susah-di-hujung-kerjaya/ Marx, K. (1959). Economic and philosophic manuscripts of 1844. Moscow: Progress Publishers. Marx, K. (1975). Karl Marx, Fredrick Engels: Collected works. New York: International Publishers. Majlis Ketua-ketua Pengajian Komunikasi. (2010). Hala tuju pengajian komunikasi dan media di Malaysia. Putrajaya: Jabatan Pengajian Tinggi, Kementerian Pengajian Tinggi.

Mohd Helmi Irwadi Mohd Nor. (2018). Gubal akta lindungi penggiat seni. myMetro. https:// www.hmetro.com.my/rap/2018/11/392541/gubal-akta-lindungi-penggiat-seni

MStar. (2011, 27 Jan). David Teo habiskan RM4.5 juta untuk beri hadiah. myStar. https:// www.mstar.com.my/spotlight/hiburan/2011/01/27/david-teo--habiskan-rm45juta-untuk-beri-hadiah

Muhamad Fairoz Azizan. (2017, 10 Jan). Berlakon bukan kerana saya taja filem Aliff Syukri. Berita Harian Online. https://www.bharian.com.my/taxonomy/ term/8/2017/01/232767/berlakon- bukan-kerana-saya-taja-filem-aliff-syukri.

Muhammad Faliq Abdul Razak, \& Rohaida Nordin. (2018). The right to health: Discriminatory treatment against migrant workers in Malaysia. Jurnal Undang-undang dan Masyarakat, 23(1), 15-24.

Nadia Azam. (2017, Disember 10). Ramai artis nampak saja mewah tapi sebenarnya.. Malaysiakini. https://www.malaysiakini.com/hiburan/405005

Nadia Azam. (2019, Disember 4). Tak ada hinanya tinggal di PPR, kata Sheila Mambo. Malaysiakini. https://www.malaysiakini.com/hiburan/502396

Natasha Dzulkalnine, Mohamed Nor Azhari, Khuan Wai Bing, Nurul Fadly Habidin, \& Abdul Rahman Ayub. (2016). Issues of payment procurement process for Industrialised Building System (IBS) project. Jurnal Teknologi. (78), 10-15.

Nazruzila Razniza Mohd Nadzri, \& Kamal Halili Hassan. (2019). Model perkembangan undang-undang buruh Australia: Panduan untuk Malaysia. Journal of Southeast Asia Social Sciences and Humanities, 89(2), 62-63.

Neilan, C. (2012, 7 Jun). TV freelancers feel the strain. Broadcast. https://www.broadcastnow. co.uk/tv-freelancers-feel-the-strain/5043059.article.

Nur Asyikin Mayudin. (2021, Mac 6). Kerja selesai tapi bayaran tak dapat, Nabila Huda 'fed up' dengar alasan produser tak profesional - "Aku geli bergaduh sebab duit... buruk perangai tapi itu gaji aku!". myStar. https://www.mstar.com.my/spotlight/ hiburan/2021/03/06/kerja-selesai-tapi-bayaran-tak-dapat-nabila-huda-fed-updengar-alasan-produser-tak-profesional---aku-geli-bergaduh-sebab-duit-burukperangai-tapi-itu-gaji-aku

Kementerian Komunikasi dan Multimedia. Pakej Rangsangan Industri Kreatif(PRISMA). (2021). Dicapai daripada https://www.kkmm.gov.my/awam/prisma

Paul, A., \& Kleingartner, A. (1994). Flexible production and the transformation of industrial relations in the motion picture and television industry. ILR Review, 47(4), 663-678.

Percival, N., \& Hesmondhalgh, D. (2014). Unpaid work in the UK television and film industries: Resistance and changing attitudes. European Journal of Communication, 29(2), 188-203. 
Qarami Hashim. (2020, Mei 15). “Gaji mereka pun RM3,000 dipecahkan tiga kali bayar" Diana Danielle simpati nasib anak seni terumbang-ambing, 'struggle' teruskan hidup. myStar. https://www.mstar.com.my/spotlight/hiburan/2020/05/15/gaji-merekapun-rm3000-dipecahkan-tiga-kali-bayar---diana-danielle-simpati-nasib-anak-seniterumbang-ambing-039struggle039-teruskan-hidup

Rafiq Mazlan. (2018, Mac 2). Cuba bela nasib anak seni, pelakon ben ali kongsikan 9 idea tambah baik kehidupan mereka yang bergelar artis. Media Hiburan. https://www. mediahiburan.my/cuba-bela-nasib-anak-senii-pelakon-ben-ali-beri-9- i d e a tambah-baik-kehidupan-mereka-yang-bergelar-artis/

Rahimin Affandi Abd Rahim, Abdullah Yusof \& Nor Adina Abdul Kadir. (2012). Film sebagai pemankin pembangunan peradaban Melayu-Islam Modern. Media Syari'ah, 14(1), 175-282.

Raja Nurfatimah Mawar Mohamed. (2017). Hampir 2 bulan kerja tanpa gaji - Risteena. Berita Harian Online. https://www.bharian.com.my/node/276904

Raja Nurfatimah Mawar Mohamed \& Fatin Farhana, Ariffin. (2020, Januari 13). Teman Aqish mula menjauh. Berita Harian Online. https://www.bharian.com.my/hiburan/ selebriti/2020/01/646381/teman-aqish-mula-menjauh

Ravid, S. A. (1999). Information, blockbusters, and stars: a study of the film industry. The University of Chicago Press Journals, 72(4), 463-492.

Ridzuan Abdul Rahman. (2021, Januari3). Debaran berganda Awie. myMetro. https://www. hmetro.com.my/utama/2021/01/659601/debaran-berganda-awie

Rolston, C. P., \& Herrera, D. (2000). The critical role of university-sponsored internships for entry into the professional music business: A report of a national survey. The Journal of Arts Management, Law, and Society 30 (2): 102-112.

Rozdan Mazalan \& Mohd Aizat Shamsuddin. (2017, Oktober 4). Isu filem tak laku: kandungan, strategi pemasaran, promosi main peranan. Berita Harian Online. https://www.bharian. com.my/hiburan/lain-lain/2017/10/333411/isu-filem-tak-laku-kandunganstrategi-pemasaran-promosi-main

Rowlands, L. (2009). The Life of Freelance Film Production Workers in the New Zealand Film Industry. Wellington, New Zealand: Massey University. Unpublished Master Thesis.

Rudy Imran Shamsudin. (2019). Filem Sangkar Babit Empat Produksi Tempatan. Dicapai daripada https://www.hmetro.com.my/rap/2019/07/476171/filem-sangkar-babit-empatproduksi-tempatan.

Sayer, S. (2011). Marx and alienation: Essays on hegelian themes. Britain: Palgrave Macmillan.

Schober, M. F., Conrad, F. G., Antoun, C., Ehlen, P., Fail, S., Hupp, A. L., Johnston, M., Vickers, L., Yanna Yan, H., \& Chan Zang (2015). Precision and disclosure in text and voice interviews on smartphones. PLOS ONE 10(1371). doi.org/10.1371/journal.pone.0128337

FINAS (2021). Senarai projek Dana Kandungan Digital yang diluluskan bagi tahun 2020 FINAS. https://www.finas.gov.my/en/senarai-projek-dana-kandungan-digitaldkd-yang-diluluskan-bagi-tahun-2020/

Serimah Mohd Sallehuddin. (2020, Jun 4). Pierre kecewa. Berita Harian Online. https://www. bharian.com.my/hiburan/selebriti/2020/06/696109/pierre-kecewa

Siebert, S., \& Wilson, F. (2013). All work and no pay: consequences of unpaid work in the creative industries. Work, Employment and Society 27 (4), 711-721. 
Siti Azira Abd. Aziz. (2009, November 15). Finas ambil alih tiga projek filem 'terbengkalai'. MStar. https://www.mstar.com.my/spotlight/hiburan/2009/11/15/finas-ambil-alih-tigaprojek-filem-terbengkalai

Siti Nur Mas Erah Amran. (2018, November 20). Lantik perunding Syariah pantau pembikinan filem: Mufti Wilayah Persekutuan. Berita Harian Online. Dicapai daripada https://www. bharian.com.my/hiburan/wayang/2018/11/499950/lantik-perunding-syariah-pantaupembikinan-filem-mufti-wp

Strauss, W. (2005). What life's like for TV's freelancers. Dicapai daripada bit.ly/fOZZj2.

Syafil Syazwan Jefri. (2019). Jadual kerja padat. myMetro. Dicapai daripada https://www. hmetro.com.my/utama/2019/08/484988/jadual-kerja-padat

USG Film Alliance Task Force. (2014). Georgia film and television industry workforce education study: data analysis and summary report. University System of Georgia Board of Regents. https://cmii.gsu.edu/files/2017/09/Beck-USG-FINAL-Film-Report-2014.pdf

Weiss, P. R. \& Faulkner, R. R. (1983). Credits and craft production: freelance social organization in the Hollywood film industry, 1964-1978. Symbolic Interaction, 6(1), 111-123 